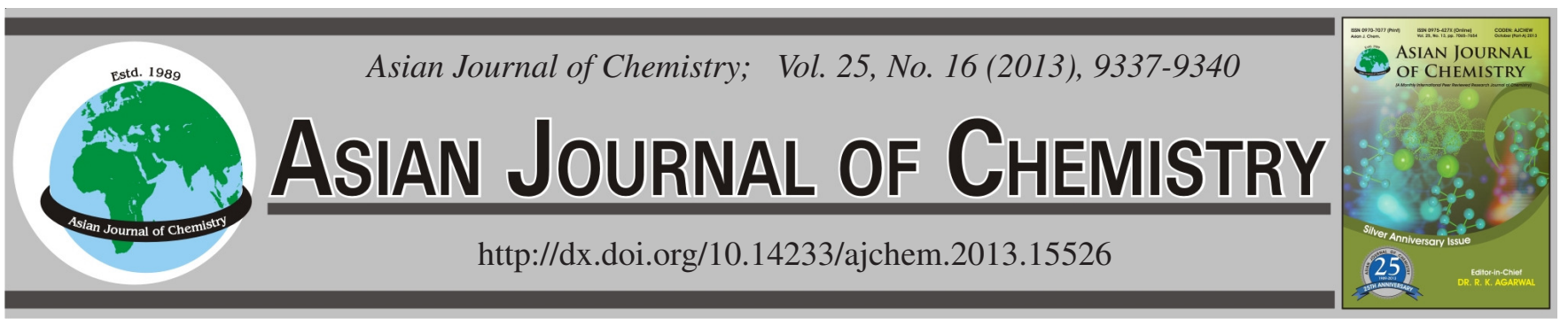

\title{
Total Phenols, Antioxidant Potential and Tyrosinase Inhibitory Activity of Walnut (Juglans regia L.) Leaf, Husk and Seed
}

\author{
M. $\operatorname{AKIN}^{1}$, G. ArABACI ${ }^{2}$ and N. SAKI ${ }^{1, *}$
}

${ }^{1}$ Department of Chemistry, Kocaeli University, Kocaeli, Turkey

${ }^{2}$ Department of Chemistry, Sakarya University, Sakarya, Turkey

*Corresponding author: Fax: +90 11 2623032003; Tel: +90 11 2623032064; E-mail: neslihansaki@gmail.com

\begin{abstract}
The present study reports the total phenolic contents, antioxidant potentials and tyrosinase inhibitory activity of the leaf, green husk and seed of walnut (Juglans regia L.) produced in Turkey. The total phenolic contents and antioxidant activity studies were carried out at two different extraction times ( 2 and $18 \mathrm{~h}$ ) while the anti-tyrosinase activity was investigated at $2 \mathrm{~h}$ extraction time. For both extraction times, leaf extracts showed the highest amount of phenols [121.08 and $133.05 \mathrm{mg} / \mathrm{g}$ of gallic equivalent (GAE)] and DPPH (2,2-diphenyl-1picrylhydrazyl) scavenging activity $\left(86.66\right.$ and $93.33 \%$ ), respectively and the inhibitory efficiency of leaf extract $\left(\mathrm{IC}_{50} 3.99 \mathrm{mg} / \mathrm{mL}\right) \mathrm{was}$ determined to be much stronger than the seed and husk extracts. The inhibition type and $\mathrm{K}_{\mathrm{i}}$ values were determined for the extracts. The results of this study suggested that walnut leaf, husk and seed can be used as an excellent, easily accessible source of natural antioxidant as well as the tyrosinase inhibitor.
\end{abstract}

Key Words: Juglans regia L., Total phenols, Antioxidant potential, Tyrosinase activity, Walnut.

\section{INTRODUCTION}

There has been growing interest over the discovery and utilization of antioxidants from natural sources such as fruits and vegetables, because several studies have documented the potential toxicity associated with the synthetic antioxidants. Most antioxidants are phenolic substances, in fact, it has been shown that there is a direct relationship between the total phenolic content and antioxidant activity in fruits and vegetables. Also, the remarkable tyrosinase inhibitory activities of polyphenols have been reported by several studies ${ }^{1,2}$.

Recent epidemiological studies have suggested that increased consumption of plant-derived, antioxidant-rich foods, decrease the risk of degenerative diseases by reduction of oxidative stress and inhibition of macromolecular oxidation $^{3,4}$. In addition, they have also been used in food and cosmetic industry by the inhibition of tyrosinase enzyme and there is a serious effort to search for natural tyrosinase inhibitors like plants because they are free of harmful side effects and can be obtained at a low $\operatorname{cost}^{5-7}$.

Among the dietary plants, walnut (Juglans regia L.) is a well-known member of Juglandaceae family. It has a remarkable nutritional composition with rich phenolic compounds. Different studies have proved that isolated polyphenols obtained from walnuts have strong antioxidant effects and they are commonly consumed in Turkey ${ }^{8-10}$.
The main purpose of this work was to examine the total phenolic contents, antioxidant potential and tyrosinase inhibitory activity of walnut's leaf, husk and seed. As far as could be determined, this is the first time that the effect of different extraction times on total phenolic content and radical scavenging activity of walnut seed, husk and leaf have been evaluated. In addition, anti-tyrosinase activity of all three parts of the walnut in a single paper are reported here.

\section{EXPERIMENTAL}

Walnut (J. regia L.) leaves, green husks and seeds were collected in November 2011 in Gebze-Kocaeli (Marmara region of Turkey). The materials were washed with tap water, dried in a dark room over a week, frozen and stored at $-20{ }^{\circ} \mathrm{C}$ for further use.

Two gram of each plant material (walnut's leaves, husks and seeds) was extracted with $25 \mathrm{~mL}$ methanol at 2 and $18 \mathrm{~h}$ separately at room temperature for total phenols determination and antioxidant activity assays. The extracts were placed in a centrifuge for $5 \mathrm{~min}$ at $5000 \mathrm{rpm}$ twice, filtered, concentrated under reduced pressure in a rotavapor and then frozen, followed by lyophilization. In addition, the same plant materials were extracted at $2 \mathrm{~h}$ with $50 \mathrm{~mL} 50 \%$ aqueous solution of methanol for tyrosinase enzyme inhibition assay. The same procedure was applied for each of these extracts ${ }^{10}$. 
Total phenolic contents: Determination of total phenolic contents of walnut' leaves, husks and seeds were determined by using the Folin-Ciocalteu's phenol reagent, according to the procedure previously described by Singleton and Rossi ${ }^{11}$ with slight modifications. Briefly, $1 \mathrm{~mL}$ of Folin-Ciocalteu's phenol reagent was added to $1 \mathrm{~mL}$ of plant extracts and mixed for $5 \mathrm{~min}$. After the addition of $1 \mathrm{~mL}$ sodium carbonate solution, the mixture was adjusted to $10 \mathrm{~mL}$ with distilled water. After $2 \mathrm{~h}$ incubation the absorbance was read at $725 \mathrm{~nm}$ by an Optizen UV spectrophotometer. A calibration curve was prepared using a standard solution of gallic acid (0.01-0.4 mM). The results were expressed as $\mathrm{mg}$ of gallic acid equivalents (GAE) per g of lyophilized extract ${ }^{12}$.

Determination of DPPH radical scavenging activity: The capacity to scavenge the DPPH free radical was monitored according to a method reported ${ }^{13}$. An aliquot $(1 \mathrm{~mL})$ of appropriately diluted extracts of walnut was mixed with $4 \mathrm{~mL}$ of $6 \times 10^{-5} \mathrm{M}$ DPPH solution. After $1 \mathrm{~h}$ incubation the absorbance was measured at $517 \mathrm{~nm}$ for 2 and $18 \mathrm{~h}$ extracts separately. The percentage of absorbance inhibition (I \%) at $517 \mathrm{~nm}$ was calculated using the equation ${ }^{10}$ :

$$
\text { I \% }=\left[\left(\mathrm{A}_{\text {blank }}-\mathrm{A}_{\text {sample }}\right) / \mathrm{A}_{\text {blank }}\right] \times 100
$$

Tyrosinase inhibitory assay: Tyrosinase inhibitory activities of the extracts were determined as described by Chan et al. ${ }^{14}$ using a modified dopachrome method with L-DOPA as the substrate. Briefly, the mixture of $40 \mathrm{U}$ mushroom tyrosinase and $0.5 \mathrm{mM} \mathrm{L-DOPA}$ with or without the extracts of different concentrations $(1.33,6.66$ and $13.33 \mathrm{mg} / \mathrm{mL})$ in 0.1 $\mathrm{M}$ phosphate buffer ( $\mathrm{pH}$ 6.8) were prepared. Without any incubation, the absorbance was measured at $475 \mathrm{~nm}$ for $1 \mathrm{~min}$ with the UV spectrophotometer. The inhibitory activities of the samples were expressed as the concentration at which $50 \%$ of the enzyme activity was inhibited $\left(\mathrm{IC}_{50}\right)$. The inhibition types were assayed by the Lineweaver-Burk plot and the inhibition constants $\left(\mathrm{K}_{\mathrm{i}}\right)$ were determined by the slope versus concentrations of the inhibitors ${ }^{15}$. Kojic acid in different concentrations $\left(25 \times 10^{-4}, 5 \times 10^{-4}\right.$ and $\left.12.5 \times 10^{-4} \mathrm{mM}\right)$ dissolved in phosphate buffer was used as a positive control and a minimum of two measurements were taken for each concentration.

Statistical analysis: Statistical analysis was performed using Statistical Package for Social Sciences (SPSS version16.0) for Windows. Comparisons between two groups were performed by unpaired $t$-test. Significance was accepted at $p$ lower than 0.05 .

\section{RESULTS AND DISCUSSION}

Total phenolic contents: Walnut grown in many regions of Turkey has a fairly common uses with a high nutritional value and the phenolic compounds are the most important group of therapeutically active constituents of this fruit. In several researches, total phenolic content of different parts of the walnut has been determined by using the Folin-Ciocalteu method ${ }^{12,16}$. Mahoney et al. ${ }^{17}$, Stampar et al. ${ }^{18}$ and Pereira et al. ${ }^{19}$ identified chlorogenic acid, caffeic acid, $p$-coumaric acid, ferulic acid, sinapic acid (hydroxy cinnamic acids), ellagic acid and syringic acid (hydroxy benzoic acids) as well as syringaldehyde (hydroxy benzaldehyde) and juglone in walnut seed, green husk and leaf. In the present work total phenolic contents in the methanolic extracts of walnut leaf, seed and husk were investigated at two different extraction times ( 2 and $18 \mathrm{~h}$ ) and the results were presented in Table- 1 . For both the extraction times, leaf extracts showed the highest amount of phenolic compounds with 121.08 and $133.05 \mathrm{mg} / \mathrm{g}$ of GAE, followed by seeds with 44 and $50.35 \mathrm{mg} / \mathrm{g}$ of GAE and husks 26.2 and $29.5 \mathrm{mg} / \mathrm{g} \mathrm{GAE}$. While the extraction yields at 2 and $18 \mathrm{~h}$ were 29.27 and $30.64 \%$ for leaf, 21.12 and $32.94 \%$ for seed and 32.87 and $36.17 \%$ for husk extracts, respectively.

\begin{tabular}{|c|c|c|}
\hline \multicolumn{3}{|c|}{$\begin{array}{c}\text { TABLE-1 } \\
\text { EXTRACTION YIELD AND PHENOLIC CONTENTS } \\
\text { OF METHANOLIC EXTRACTS OF WALNUT } \\
\text { LEAF, SEED AND HUSK }\end{array}$} \\
\hline Samples & Extraction yield (\%) & Phenolic content (mg GAE/g) \\
\hline \multicolumn{3}{|c|}{ Extraction time $(2 \mathrm{~h})$} \\
\hline Leaf & $29.27 \pm 0.15^{\mathrm{a}}$ & $121.08 \pm 1.07^{\mathrm{a}}$ \\
\hline Seed & $21.12 \pm 0.17^{\mathrm{b}}$ & $44.11 \pm 1.38^{b}$ \\
\hline Husk & $32.87 \pm 0.94^{\mathrm{a}}$ & $26.21 \pm 1.67^{\mathrm{c}}$ \\
\hline \multicolumn{3}{|c|}{ Extraction time $(8 \mathrm{~h})$} \\
\hline Leaf & $30.64 \pm 0.65^{\mathrm{a}}$ & $133.05 \pm 1.98^{b}$ \\
\hline Seed & $32.94 \pm 0.28^{\mathrm{b}}$ & $50.35 \pm 1.82^{\mathrm{c}}$ \\
\hline Husk & $36.17 \pm 0.79^{b}$ & $29.50 \pm 1.64^{\mathrm{a}}$ \\
\hline
\end{tabular}

DPPH free radical scavenging activity: Antioxidants, in other words radical scavengers, are believed to intercept the free radical chain of oxidation and are able to donate hydrogen from the phenolic hydroxyl groups to DPPH. Free radical scavenging of phenolic compounds is an important property underlying their various biological activities ${ }^{20}$.

Walnut being as a rich natural antioxidant source of fruit has been used as a medicinal treatment plant in many cultures since ancient times. A previous study showed that walnut had the highest antioxidant activity among the analyzed foods and drinks commonly consumed in Turkey ${ }^{8}$. Pereira et al. ${ }^{12}$ investigated the chemical composition of aqueous extracts of six walnut cultivars by the scavenging effect on DPPH radicals and all walnut extracts exhibited antioxidant capacity.

On the other hand, the antioxidant activities of walnut green husk extracts were determined on five different cultivars and a concentration dependent antioxidative capacity was verified in reducing power and DPPH assays ${ }^{16}$. Fig. 1 shows the effect of different extraction times on the DPPH scavenging activity in walnut leaf, seed and husk methanolic extracts. For 2 and $18 \mathrm{~h}$ extraction times, DPPH free radical scavenging capacities are for leaf 86.66 and $93.33 \%$, for seed 84.615 and $92.30 \%$ and for husk extracts 85.714 and $85.12 \%$, respectively. While a longer extraction time caused an increase on the scavenging effect of DPPH radicals for walnut leaf and seed extracts, it had no effect on walnut husks extracts.

Tyrosinase inhibition: As being the largest groups in tyrosinase inhibitors and flavanoids, polyphenols are widely distributed in the leaves, seeds, bark and flowers of plants ${ }^{21}$. Among these plants, walnut has been reported to be rich in flavonoids and phenolic acid and therefore, it is an excellent example to be developed as a tyrosinase inhibitor ${ }^{22,23}$. Özer et al. ${ }^{1}$ investigated the inhibitory effect of methanol extracts of Cortex Castanea (Castanea sativa) stem bark, Folium Eucalypti 


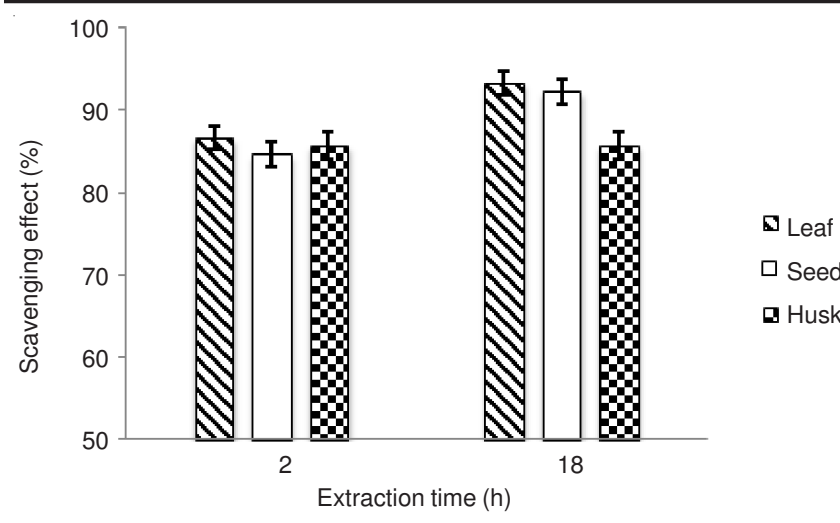

Fig. 1. DPPH scavenging activity (\% inhibition) of walnut leaf, seed and husk methanol extracts. Each value expressed as mean \pm standard deviation $(\mathrm{n}=3)$

(Eucalyptus camaldulensis) leaves and Folium Juglandis (Juglans regia) leaves on tyrosinase activity. The results showed that Folium Juglandis (Juglans regia) extract caused the highest inhibition of tyrosinase enzyme.

In the present work the tyrosinase inhibitory activity of walnut leaf, seed and husk extracts at $2 \mathrm{~h}$ extraction time were examined. Their inhibitory activity was tested against tyrosinase for the oxidation of L-DOPA and all extracts showed inhibitory activity. Even though, tyrosinase inhibitory activity of walnut leaf extracts has been shown as tyrosinase inhibitors earlier. To our best of knowledge, seed and husk extracts, inhibitory activities are reported for the first time with their $\mathrm{IC}_{50}$ values and inhibition types. Fig. 2 shows the comparison of the \% inhibition effects of walnut leaf, husk and seed extracts on tyrosinase enzyme. $\mathrm{IC}_{50}$ values for leaf, seed and husk extracts showed inhibitory activity of $3.99,8.837$ and 10,154 $\mathrm{mg} / \mathrm{mL}$ and the inhibition constants $\left(\mathrm{K}_{\mathrm{i}}\right)$ were found as 3.78 , 9.665 and 12.66, respectively. The results are summarized in Table-2. As shown in Fig. 3, inhibition types of the extracts were also determined by drawing Lineweaver-Burk pilots and identified as the competitive, mixed and noncompetitive types for leaf, seed and husk extracts, respectively. In the study, kojic acid was used as the positive control. $\mathrm{IC}_{50}$ value and the inhibition type determined for kojic acid was in parallel with the literature as $0.079 \mathrm{mg} / \mathrm{mL}$ and mixed type inhibition ${ }^{24}$.

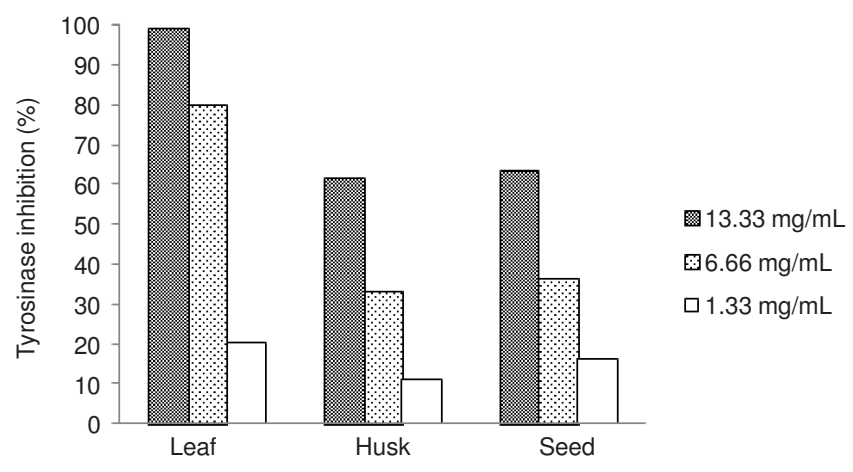

Fig. 2. Comparison of the walnut leaf, seed and husk water extracts $\%$ inhibision effects on tyrosinase enzyme

\section{Conclusion}

The effect of different extraction times on the antioxidant activity and the total phenol content in the walnut's leaf, husk
TABLE-2

TYROSINASE INHIBITORY ACTIVITIES OF WATER EXTRACTS OF WALNUT LEAF, SEED AND HUSK

\begin{tabular}{lccc}
\hline & $\begin{array}{c}\mathrm{IC}_{50} \\
(\mathrm{mg} / \mathrm{mL})\end{array}$ & Inhibition type & $\begin{array}{c}\text { Inhibition constant } \\
(\mathrm{mg} / \mathrm{mL})\end{array}$ \\
\hline Leaf & 3.990 & Competitive & 3.780 \\
Seed & 8.837 & Mixed & 7.615 \\
Husk & 10.134 & Noncompetitive & 9.665 \\
Kojic acid & 0.790 & Mixed & 0.540 \\
\hline
\end{tabular}
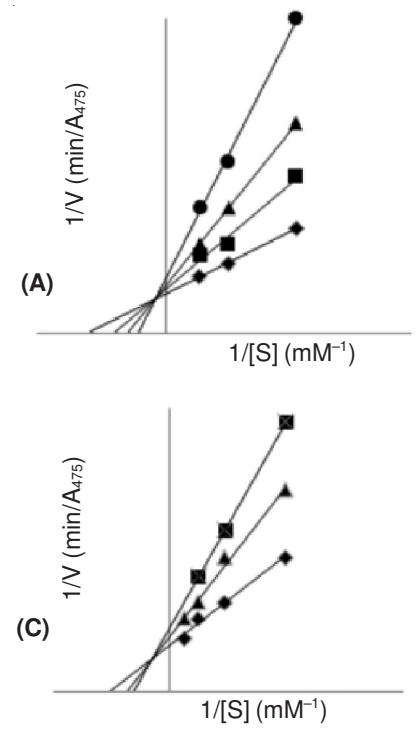

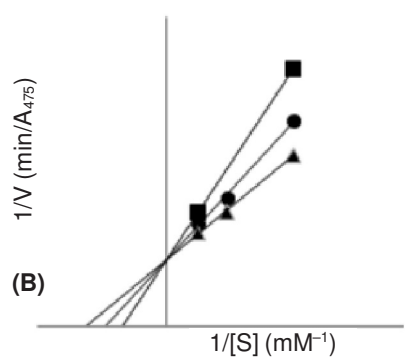

(D)

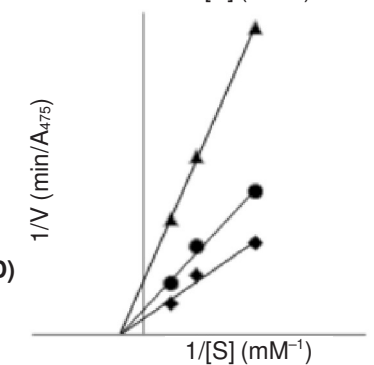

Fig. 3. Lineweaver-Burk plots for the catalysis of L-DOPA by mushroom tyrosinase concentrations of each tested extracts for plots (A) Kojic acid $0,0.0025,0.05,0.125 \times 10 \mathrm{mg} / \mathrm{mL}$; (B) Leaf $0,1.33,2,66 \mathrm{mg} /$ $\mathrm{mL}$; (C) Seed 0, 6.66, $13.33 \mathrm{mg} / \mathrm{mL}$; (D) Husk 0, 6.66, $20 \mathrm{mg} / \mathrm{mL}$

and seed for the first time. As a part of the study, antityrosinase activity has also been examined to determine the inhibition types, $\mathrm{IC}_{50}$ values and $\mathrm{K}_{\mathrm{i}}$ constants of walnut seed, green husk and leaf. The activity of all three parts of the walnut in a single paper are reported first time. The results of this research suggest that walnut can be used as an inexpensive and easily accessible source of effective natural antioxidants as well as the tyrosinase inhibitor.

\section{REFERENCES}

1. O. Ozer, B. Mutlu and B. Kivcak, Pharm. Biol., 45, 519 (2007).

2. N. Niciforovic, V. Mihailovic, P. Maskovic, S. Solujic, A. Stojikovic and D.P. Muratspahic, Food Chem. Toxicol., 48, 3125 (2010).

3. B. Golding, B. Glasson, S.G. Wylie and D. Leach, J. Agric. Food Chem., 49, 2283 (2001).

4. D.L. McKay, C.-Y.O. Chen, K. Yeum, N.R. Matthan, A.H. Lichtenstein and J.B. Blumberg, Nutr. J., 9, 1 (2010).

5. Y. Chu, J. Sun, X. Wu and R.H. Liu, J. Agric. Food Chem., 50, 6910 (2002).

6. U. Gawlik-Dziki, U. Zlotek and M. Swieca, Food Chem., 107, 129 (2008).

7. M.E. Chiari, M.B. Joray, G. Ruiz, S.M. Palacios and M.C. Carpinella, Food Chem., 120, 10 (2010).

8. D. Shahwar, M. Naz, M.A. Raza, G. Ara, A. Yasmeen, A. Saeed, S. Bokhari, M. Ajaib and N. Ahmad, Asian J. Chem., 24, 3151 (2012).

9. E. Altuntas and M. Erkol, Int. J. Food Eng., 5, 1 (2009).

10. M. Carvalho, P.J. Ferreira, V.S. Mendes, R. Silva, J.A.Pereira, C. Jeronimo and B.M. Silva, Food Chem. Toxicol., 48, 441 (2010).

11. V.L. Singleton and J.A. Jr. Rossi, Am. J. Enol. Viticult., 16, 144 (1965).

12. J.A. Pereira, I. Oliveira, A. Sousa, I.C.F.R. Ferreira, A. Bento and L. Estevinho, Food Chem. Toxicol., 46, 2103 (2008).

13. T. Hatano, H. Kagawa, T. Yasuhara and T. Okuda, Chem. Pharm. Bull., 36, 2090 (1988). 
14. E.W.C. Chan, Y.Y. Lim, L.F. Wong, F.S. Lianto, S.K. Wong, K.K. Lim, C.E. Joe and T.Y. Lim, Food Chem., 109, 477 (2008).

15. L. Qiu, J.X. Zhuang, X. Zhong, J.J. Zhou, Y.L. Guo and Q.X. Chen, Food Chem., 112, 609 (2009).

16. I. Oliveira, A. Sousa, I.C.F.R. Ferreira, A. Bento, L. Estevinho and J.A. Pereira, Food Chem. Toxicol., 46, 2326 (2008).

17. N. Mahoney, R.J. Molyneux and B.C. Campbell, J. Agric. Food Chem., 48, 4418 (2000)

18. F. Stampar, A. Solar, M. Hudina, R. Veberic and M. Colaric, Food Chem., 95, 627 (2006).

19. J.A. Pereira, I. Oliveira, A. Sousa, P. Valentao, P.B. Andrade, I.C.F.R. Ferreira, F. Ferreres, A. Bento, R. Seabra and L. Estevinho, Food Chem. Toxicol., 45, 2287 (2007).
20. L.A. Marghitas, O.G. Stanciu, D.S. Dezmirean, O. Bobis, O. Popescu, S. Bogdanov and M.G. Campos, Food Chem., 115, 878 (2009).

21. A. Rescigno, F. Bruyneel, A. Padiglia, F. Sollai, A. Salis, J. MarchandBrynaert and E. Sanjust, Biochim. Biophys. Acta, 1810, 799 (2011).

22. K. Maeda and M.J. Fukuda, Soc. Cosmetic Chem., 42, 361 (1991).

23. J.K. Hwang, T.W. Kong, N.I. Baek and Y.R. Pyun, Planta Med., 66, 273 (2000).

24. T.S. Chang, Int. J. Mol. Sci., 10, 2440 (2009). 